\title{
Secagem de placas cerâmicas híbridas argila/rejeito de diatomita: Um estudo experimental
}

\author{
Drying of clay/diatomite hybrid ceramic plates: An experimental study \\ Secado de placas de cerámica híbrida de arcilla/diatomita: Un estudio experimental
}

Recebido: 14/06/2021 | Revisado: 19/06/2021 | Aceito: 22/06/2021 | Publicado: 08/07/2021

Raniere Fernandes Costa

ORCID: https://orcid.org/0000-0002-5831-4251 Universidade Federal de Campina Grande, Brasil

E-mail: ranierengenharia.costa@gmail.com

Alysson Dantas Ferreira

ORCID: https://orcid.org/0000-0003-0029-8364 Universidade Federal de Campina Grande, Brasil

E-mail: alysson.dantas@eq.ufcg.edu.br

José Jorge da Silva Junior

ORCID: https://orcid.org/0000-0003-4497-5689

Universidade Federal de Campina Grande, Brasil

E-mail: josejorge_18@hotmail.com

Pedro Mateus Aguiar Barbosa

ORCID: https://orcid.org/0000-0001-8587-365X

Universidade Federal de Campina Grande, Brasil

E-mail: pedromatheus1234@gmail.com

Diego José Araújo Bandeira

ORCID: https://orcid.org/0000-0002-6245-9875

Universidade Federal de Campina Grande, Brasil

E-mail: diegoimperium8@gmail.com

Maria Luiza de Souza Rezende

ORCID: https://orcid.org/0000-0002-6189-9924

Universidade Federal de Campina Grande, Brasil

E-mail: mluizarezende@hotmail.com

José Jefferson da Silva Nascimento

ORCID: https://orcid.org/0000-0002-2620-6491

Universidade Federal de Campina Grande, Brasil E-mail: jeffpesquisador@gmail.com

\section{Resumo}

Na produção de tijolos cerâmicos, tem-se na etapa de secagem um maior destaque por ser substancial no processo, uma vez que a qualidade do produto está relacionada diretamente a essa etapa. A secagem em tijolos cerâmicos maciços com diferentes percentuais de rejeitos de diatomita, foi experimentalmente realizada em uma estufa com circulação de ar forçada. Os experimentos foram realizados baseados em um planejamento experimental fatorial $2^{\mathrm{k}}$ como fatores de entrada, a temperaturas do ar $\left(60\right.$ e $\left.110{ }^{\circ} \mathrm{C}\right)$, a homogeneidade da mistura $(30$ e $60 \mathrm{~min})$ e a porcentagem do rejeito (10 e $30 \%$ ). A partir da matriz dos resultados, analisou-se estatisticamente a influência dos parâmetros do planejamento sobre o comportamento da umidade. A cerca dos resultados do processo de secagem dos tijolos cerâmicos, concluísse que a temperatura é o principal parâmetro que controla a retirada de umidade do material. Foi observado que o rejeito de diatomita diminui a retenção de água nos corpos de prova, sendo os melhores resultados encontrados para as misturas com 30\% de rejeito. Entretanto, verificou-se o inverso para o tempo de homogeneização, havendo a tendência de maior retenção de água para maiores tempos.

Palavras-chave: Tijolos cerâmicos maciços; Comportamento da umidade; Processo de secagem; Tempo de homogeneização; Temperatura.

\begin{abstract}
In the production of ceramic bricks, the drying stage has a greater prominence for being substantial in the process, since the quality of the product is directly related to this stage. Drying on solid ceramic bricks with different percentages of diatomite tailings was experimentally carried out in an oven with forced air circulation. The experiments were carried out based on a $2 \mathrm{k}$ factorial experimental design as input factors, at air temperatures (60 and $\left.110{ }^{\circ} \mathrm{C}\right)$, the homogeneity of the mixture $(30$ and $60 \mathrm{~min})$, and the percentage of waste $(10$ and $30 \%)$. From the matrix of results, the influence of the planning parameters on the moisture behavior was statistically analyzed. About the results of the drying process of ceramic bricks, it was concluded that temperature is the main parameter that controls the removal of moisture from the material. It was observed that diatomite tailings reduce water retention in the
\end{abstract}


specimens, with the best results being found for mixtures with $30 \%$ tailings. However, the inverse was verified for the homogenization time, with a tendency of greater water retention for longer times.

Keywords: Solid ceramic bricks; Humidity behavior; Drying process; Homogenization time; Temperature.

\section{Resumen}

En la producción de ladrillos cerámicos, la etapa de secado tiene un mayor protagonismo por ser sustancial en el proceso, ya que la calidad del producto está directamente relacionada con esta etapa. El secado sobre ladrillos cerámicos macizos con diferentes porcentajes de relaves de diatomita se realizó experimentalmente en un horno con circulación de aire forzado. Los experimentos se realizaron en base a un diseño experimental factorial $2 \mathrm{k}$ como factores de entrada, a temperaturas del aire $\left(60\right.$ y $\left.110^{\circ} \mathrm{C}\right)$, la homogeneidad de la mezcla $(30$ y $60 \mathrm{~min})$ y el porcentaje de desperdicio (10 y $30 \%)$. A partir de la matriz de resultados, se analizó estadísticamente la influencia de los parámetros de planificación sobre el comportamiento de la humedad. Sobre los resultados del proceso de secado de los ladrillos cerámicos, se concluyó que la temperatura es el principal parámetro que controla la remoción de humedad del material. Se observó que los relaves de diatomita reducen la retención de agua en los especímenes, encontrándose los mejores resultados para mezclas con $30 \%$ de relaves. Sin embargo, se verificó lo inverso para el tiempo de homogeneización, con tendencia a una mayor retención de agua durante tiempos más prolongados.

Palabras clave: Ladrillos cerámicos macizos; Comportamiento de la humedad; Proceso de secado; Tiempo de homogeneización; Temperatura.

\section{Introdução}

O aumento da necessidade de argila (principal matéria-prima) por parte da indústria cerâmica tem provocado impactos ao meio ambiente, tais como a redução do volume de matéria-prima das jazidas e diminuição de sua vida útil, possibilidade de alteração de paisagem e destruição da natureza da região da jazida, entre outros (Almeida, et al., 2020).

Alguns resíduos minerais são considerados adequados para a produção de cerâmica (Sokolár, et al., 2012) devido ao seu baixo custo, propriedades físico-químicas e capacidade de causar uma redução na temperatura necessária para a sinterização do processo. A importância da utilização de resíduos na construção civil torna-se evidente ao proporcionar uma gestão adequada desses, quando os utilizam (após beneficiamento que se dará conforme as características de cada resíduo) como matérias primas alternativas na confecção de novos materiais para atender as demandas desse setor, à medida que reduz a exploração dos recursos naturais, gerando materiais alternativos para atender suas demandas (Schackow, et al., 2015; Gameiro, et al., 2014). Assim, é essencial que haja maneiras de diminuir o impacto ambiental, como por exemplo, a incorporação de rejeitos em substituição parcial da argila (Monteiro, et al., 2005).

Dessa maneira, o uso de recursos naturais que apresentam propriedades pozolânicas ganhou grande importância na indústria da construção civil (Macedo, et al., 2020). Na fabricação de tijolos cerâmicos maciços, a adição de aditivos minerais ativos, em substituição a argila é de grande significado científico. Um desses rejeitos minerais é proveniente do beneficiamento da terra diatomácea ou (diatomita) utilizada na maioria das vezes para o tratamento de efluentes industriais, como filtro, assim como são aplicados como agente de enchimento em diferentes indústrias, na produção de tintas e de plásticos, como matériaprima para a fabricação de certos produtos térmicos, materiais isolantes acústicos e na produção de tijolos cerâmicos (Crangle, 2014).

A diatomita é uma rocha sedimentar composta principalmente de esqueletos de plantas aquáticas unicelulares microscópicas, chamadas diatomáceas. Os esqueletos são compostos de sílica amorfa (dióxido de silício, $\mathrm{SiO}$ ), uma substância muito durável (Degirmenci \& Yilmax, 2009). Sendo caracterizada como pozolana natural, pois satisfaz os requisitos da norma EN 197-1 relativos ao teor de sílica ativa. A terra de diatomáceas é muito leve, devido a sua alta porosidade, e é quimicamente inerte. Possui também baixa condutividade térmica, alto ponto de fusão, capacidade abrasiva macia, alta área de superfície e boa capacidade de absorção (Hadjar, et al., 2007).

Como as diatomitas no Brasil normalmente ocorrem associadas a argilas, areia de quartzo e óxidos de ferro, vários pesquisadores estudaram o seu beneficiamento visando a remoção dessas impurezas para obtenção de produtos que, depois de 
calcinados, possam ser usados como agente de filtração (França, et al., 2002). Essas impurezas (rejeitos) são descartadas no meio ambiente.

Uma das principais matérias-primas para a indústria cerâmica vermelha é a argila, que é utilizada para aplicações em cerâmica estrutural (blocos, tijolos e telhas) e, deve atender a requisitos de qualidade que são influenciados por suas características química, física, mineralógica e microestrutural, as quais controlam as propriedades cerâmicas dos produtos finais (Reis, 2014) e assim determinar se a argila é adequada ou não a determinado uso. A argila é um material natural, terroso, de granulometria fina, e suscetível à moldagem por apresentar consistência plástica em presença de certa quantidade de água.

O processo de produção pelo qual passa a cerâmica vermelha até que se obtenha o produto em sua forma final é composto pelas seguintes etapas, extração da argila nas jazidas, preparação da massa, conformação das peças, secagem e queima para que, posteriormente, ocorra a estocagem e/ou transporte para o consumidor (Medeiros, et al., 2014).

Durante o processo de fabricação de materiais cerâmicos, é importante compreender e controlar várias etapas: a exploração das jazidas, o tratamento prévio das matérias-primas e a homogeneização, secagem e queima da argila (Boukadida, et al., 2002). Na etapa de homogeneização, a água é adicionada à argila para plasticidade e para facilitar a moldagem das peças. A secagem é então responsável pela remoção desta água (Cadé, et al., 2005). A presença de água tem grande influência na durabilidade dos materiais de construção. É através do processo de absorção e, sobretudo, durante a secagem, que podem ocorrer danos nos materiais. A secagem é um processo de transferência de massa complexo durante o qual acontecem mudanças estruturais e físico-químicas no interior dos materiais (Barreira, et al., 2015).

Quando a produção de peças cerâmicas acontece em escala industrial, uma variável que deve ser levada em consideração refere-se ao consumo da energia gasta ao longo do processo produtivo. O consumo de energia térmica e elétrica representa, atualmente, uma grande parcela do custo total de produção dessas indústrias, estando a secagem entre as etapas que mais consomem energia (Alves, et al., 2008). Neste contexto, é fundamental conhecer os efeitos da secagem e o seu controle, uma vez que estes alteram as propriedades físicas e químicas do produto, e tais alterações afetam sensivelmente o processo de transferência de calor e massa (Nascimento, et al., 2006).

Com base no exposto, objetivou-se nesta pesquisa realizar a caracterização dos materiais utilizados (argila e rejeito de diatomita) e avaliar os efeitos da temperatura de secagem da porcentagem do rejeito de diatomita na massa de cerâmica vermelha e o tempo de homogeneização, sobre o comportamento da umidade no processo de secagem.

\section{Metodologia}

\section{Obtenção do rejeito de diatomita e argila}

O estudo foi realizado a partir de uma mistura de argila "in natura" com o rejeito de diatomita. A argila "in natura" para cerâmica vermelha foi cedida pela empresa de cerâmica São Matheus situada no município de São Gonçalo do Amarante, localizado na Região Metropolitana de Natal- RN. Os rejeitos de diatomita são provenientes do beneficiamento da produção da diatomita, doados pela empresa de mineração Mirasa Ltda, localizada no município do Rio do Fogo em Barra de Punaú, no estado Rio Grande do Norte. Os procedimentos adotados para obtenção das amostras, foram: realizar a secagem dos materiais em estufa a uma temperatura de $\pm 110{ }^{\circ} \mathrm{C}$ por 24 horas, para perder a umidade ou até atingir a constância de massa; posteriormente, foram realizadas as etapas de destorroamento e peneiramento de malha $\mathrm{n}^{\circ} 200(0,074 \mathrm{~mm})$, para realização dos ensaios de caracterização.

\section{Caracterização e a Preparação dos corpos de prova}

A caracterização da argila e do rejeito da diatomita foi feita por meio: fluorescência de raios X (FRX) em espectrômetro marca Philips modelo PW2400; difração de raios X (DRX) com fonte de cobre (radiação K $\alpha$ ) em aparelho 
Philips X-PERT MPD. A análise granulométrica por difração a laser em equipamento Cilas, modelo 1064 L/D sendo utilizado aproximadamente $5 \mathrm{~g}$ do material para obtenção da curva granulométrica em peneira malha, conforma especificado pela ABNT n²00.

A preparação da massa se deu conforme a metodologia proposta por Souza Santos (1975), a partir da secagem das matérias-primas em uma estufa a $110{ }^{\circ} \mathrm{C}$ por $24 \mathrm{~h}$. Em seguida, o rejeito e a argila foram destorroados e peneirados mecanicamente até uma fração passante de 80 mesh. Com os grãos peneirados, realizou-se uma homogeneização em moinho de bolas por 30, 45 e 60 min, adicionando $8 \%$ de umidade nas massas o suficiente para obter uma boa homogeneização e atingir o ponto plástico necessário à conformação. Foram preparadas amostras com 0,10, 20 e 30\% em massa de rejeito de diatomita. Os corpos de prova foram conformados por prensagem uniaxial em prensa hidráulica utilizando matriz de aço e pressão de $20 \mathrm{Mpa}$, moldados em massa semi-seca, com dimensões de 60 × 20 x $5 \mathrm{~mm}^{3}$ ver (Figura 1), peso de 11,82 g e densidade de $1,97 \mathrm{~g} / \mathrm{cm}^{3}$ conforme sugerido por Medeiros et al. (2014).

Figura 1 - Amostra representativa pelo AutoCad com suas dimensões 60 x 20 x 5 mm.

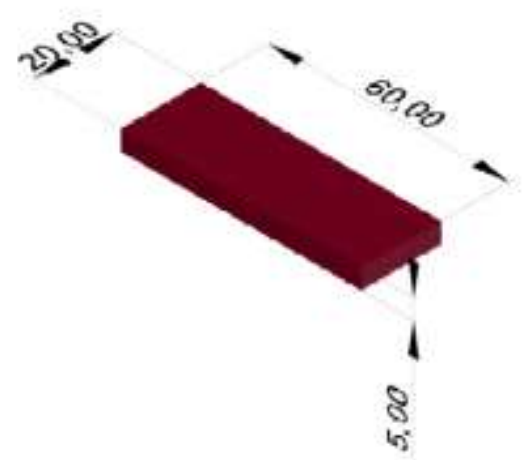

Fonte: Autores (2021).

\section{Secagem das amostras}

A secagem das amostras foi realizada em uma estufa com circulação de ar de marca MARCONI, com controlador de temperatura e com uma faixa de atuação entre $0-200^{\circ} \mathrm{C}$. Foi utilizada uma bandeja de arame galvanizado usada para acomodar as amostras visando facilitar a circulação do ar sobre elas dentro da estufa. Em intervalos pré-estabelecidos, ocorreu a retirada das amostras da estufa para medições da massa, temperatura e suas dimensões. Na primeira hora de secagem, as amostras foram retiradas em intervalos de 10 minutos, após esse período, as medições foram realizadas em intervalos de 30 minutos até a variação das massas estagnar em uma precisão de segunda casa decimal. Ao final, para ser obtida a massa de seco, as amostras foram levadas a uma secagem e esterilização (FANEM) sem circulação de ar a $110^{\circ} \mathrm{C}$ por 48 horas (Nascimento, 2002). A medição da temperatura foi feita no centro fixo de cada amostra com uma pistola térmica com escala de -50 a $1000^{\circ} \mathrm{C}$, TI 890 . A dimensão dos corpos de prova foram realizadas utilizando-se um paquímetro digital da marca Messen com precisão de $0,01 \mathrm{~mm}$ e a massa em uma balança digital Quimis BG2000, com desvio de 0,01 g e erro de 0, $1 \mathrm{~g}$. A secagem foi realizada em triplicata, onde cada experimento continha cinco amostras de tijolos cerâmicos e as condições do processo seguiram um planejamento fatorial do tipo $2^{\mathrm{k}}$. A matriz de experimento está apresentada na Tabela 1. 
Tabela 1 - Matriz de experimento do planejamento fatorial $2^{\mathrm{k}}$.

\begin{tabular}{lccc}
\hline & $\mathrm{P}[\%]$ & $\mathrm{T}\left[{ }^{\circ} \mathrm{C}\right]$ & $\mathrm{H}[\mathrm{min}]$ \\
\hline Experimento 1 & 10 & 110 & 30 \\
Experimento 2 & 10 & 110 & 60 \\
Experimento 3 & 10 & 60 & 30 \\
Experimento 4 & 10 & 60 & 60 \\
Experimento 5 & 30 & 110 & 30 \\
Experimento 6 & 30 & 110 & 60 \\
Experimento 7 & 30 & 60 & 30 \\
Experimento 8 & 30 & 60 & 60 \\
\hline
\end{tabular}

Fonte: Autores (2021).

\section{Teor de Umidade}

A partir dos dados de perda de massa das amostras durante as secagens e dos teores de umidade de equilíbrio, foram calculadas as razões de umidade a partir da Equação 1.

$$
M R=\frac{M_{d}-M_{e}}{M_{0}-M_{e}}
$$

onde $\mathrm{M}_{\mathrm{d}}$ é o teor de umidade no tempo t em minutos da secagem, Mo é o teor de umidade inicial e Me é a umidade de equilíbrio, todos dados em $\mathrm{kg}$.

\section{Resultados e Discussão}

\section{Caracterização}

Os resultados da análise química e perda ao fogo das matérias-primas são apresentadas na Tabela 2. A argila foi constituída essencialmente por de $\mathrm{SiO}_{2}$ e $\mathrm{Al}_{2} \mathrm{O}_{3}$ com valores 54,74\% e 25,031\% respectivamente. Essa composição indica a presença de silicatos e sílica livre. Observa-se, também, um teor considerável de $\mathrm{Fe}_{2} \mathrm{O}_{3}$ superior a 9\%, e que, em função disso, a argila apresenta uma coloração vermelha após a queima, visto que este óxido confere tonalidade aos corpos cerâmicos e atua na plasticidade das massas cerâmicas, assim como o $\mathrm{TiO}_{2}$, que apresentou um teor de 1,46\%. O óxido de potássio ( $\left.\mathrm{K}_{2} \mathrm{O}\right)$, com teor de $3,42 \%$, encontra-se geralmente na forma de feldspatos, sendo considerado um fundente para massas, conferindo resistência mecânica quando sintetizado entre $950^{\circ} \mathrm{C}$ e $1000^{\circ} \mathrm{C}$. Os demais óxidos com teor abaixo de $1,0 \%$ são considerados impurezas. Dessa forma, o material estudado é viável tecnicamente para produção de produtos da cerâmica vermelha.

A composição química do rejeito de diatomita apresentou alto teor de $\mathrm{SiO}_{2}$. De acordo com Goulart (2010) as amostras são classificadas como da classe A por apresentarem teor de sílica superior a $60 \%$ e uma porcentagem inferior a $15 \%$ de matéria orgânica. 
Tabela 2 - Composição química das materias primas (\% em massa).

\begin{tabular}{|c|c|c|}
\hline Componente & Argila & $\begin{array}{l}\text { Rejeito de } \\
\text { diatomita }\end{array}$ \\
\hline $\mathrm{SiO}_{2}$ & 54,745 & 88,388 \\
\hline $\mathbf{A l}_{2} \mathrm{O}_{3}$ & 25,031 & 9,065 \\
\hline $\mathrm{Fe}_{2} \mathrm{O}_{3}$ & 9,619 & 0,602 \\
\hline $\mathbf{K}_{2} \mathbf{O}$ & 3,424 & 0,125 \\
\hline MgO & 3,300 & 0,388 \\
\hline $\mathrm{CaO}$ & 1,609 & 0,407 \\
\hline $\mathrm{TiO}_{2}$ & 1,467 & 0,355 \\
\hline $\mathrm{RuO}_{2}$ & 0,286 & ------- \\
\hline $\mathrm{SO}_{3}$ & 0,192 & 0,188 \\
\hline $\mathrm{K}_{2} \mathrm{O}$ & ------- & 0,125 \\
\hline MnO & 0,135 & ------- \\
\hline $\mathrm{ZrO}_{2}$ & 0,104 & 0,012 \\
\hline $\mathbf{B a O}$ & ------- & 0,087 \\
\hline $\mathrm{Cr}_{2} \mathrm{O}_{3}$ & 0,030 & ------- \\
\hline SrO & 0,029 & ------- \\
\hline $\mathbf{R} \mathbf{b}_{2} \mathbf{O}$ & 0,018 & ------- \\
\hline $\mathbf{Y}_{2} \mathrm{O}_{3}$ & 0,012 & ------- \\
\hline Perda ao Fogo & -------- & 0,383 \\
\hline
\end{tabular}

Fonte: Autores (2021).

Na Tabela 3 é mostrada a distribuição granulométrica das amostras da argila e do rejeito de diatomita. A distribuição dos tamanhos das partículas da argila mostra que 10\% das partículas possuem diâmetros inferiores a 2,44 $\mu$ m, $50 \%$ das partículas possuem diâmetros inferiores a 20,35 $\mu \mathrm{m}, 90 \%$ das partículas possuem diâmetros inferiores a 52,71 Mm, e o diâmetro médio das partículas de 24,48 $\mu \mathrm{m}$. Dessa forma, o material tem características de material argiloso. O resultado da análise granulométrica mostra que o material possui pouca quantidade de partículas com $0,02 \mu \mathrm{m}$, tamanho dos argilominerais que são um dos elementos responsáveis pela plasticidade do material.

Tabela 3 - Valores obtidos de análise granulométrica das amostras de argila e rejeito de diatomita.

\begin{tabular}{cccc}
\hline Amostras & $\mathbf{1 0 \%}$ & $\mathbf{5 0 \%}$ & $\mathbf{9 0 \%}$ \\
\hline & Diâmetro & Diâmetro & Diâmetro \\
Argila & $<2,44 \mu \mathrm{m}$ & $<20,53 \mu \mathrm{m}$ & $<52,71 \mu \mathrm{m}$ \\
\hline Rejeito de diatomita & Diâmetro & Diâmetro & Diâmetro \\
& $<1,79 \mu \mathrm{m}$ & $<9,51 \mu \mathrm{m}$ & $<32,29 \mu \mathrm{m}$ \\
\hline
\end{tabular}

Fonte: Autores (2021).

Já a distribuição dos tamanhos das partículas do rejeito de diatomita mostram que $10 \%$ das partículas possuem diâmetros inferiores a $1,79 \mu \mathrm{m}, 50 \%$ das partículas possuem diâmetros inferior a 9,51 $\mu$ m e $90 \%$ possuem diâmetros inferiores a 32,29 $\mu \mathrm{m}$. O diâmetro médio das partículas foi de 13,28 $\mu \mathrm{m}$. Tais informações mostram que o rejeito de diatomita 
é bastante fino, garantindo uma boa superfície de contato para o meio racional, participando assim mais ativamente da reação. A finura da matéria-prima influencia em diversas propriedades da cerâmica, como graus de plasticidade, trabalhabilidade e resistência a verde, a seco e após o processo de queima (Nociti, 2011).

A diferença entre o tamanho de partículas da argila e do resíduo pode levar a melhor empacotamento no corpo de prova, pois as partículas menores tendem a preencher os vazios entre as partículas maiores, o que pode resultar em compacto com maior resistência mecânica, importante para evitar trincas durante a extração ou no manuseio anterior à queima (Rodrigues, et al., 2019).

A Figura 2 apresenta a análise mineralógica da argila através da análise de difração de raios-x, onde verificou-se uma argila caulinítica, com quartzo como principal impureza, o que reduz a plasticidade da argila. A caulinita caracteriza-se como um mineral formador de estrutura em uma ampla faixa de temperaturas de queima. Nas temperaturas entre $500^{\circ} \mathrm{C}$ e $600^{\circ} \mathrm{C}$ a caulinita perde água modificando-se a estrutura para metacaulinita, na qual, a estrutura amorfa vai eliminando $\mathrm{SiO} 2$ amorfa, com aquecimento até $950^{\circ} \mathrm{C}$, inicia-se a formação da estrutura de espinélio $\mathrm{Al}-\mathrm{Si}$ com composição $2 \mathrm{Al}_{2} \mathrm{O}_{3} \cdot 3 \mathrm{SiO}_{2}$. O quartzo diminui a retração da massa, já que durante a formação de fase líquida se comporta como o esqueleto dos corpos cerâmicos (Monteiro, et al., 2017).

Figura 2 - Difratograma de raios-X da argila.

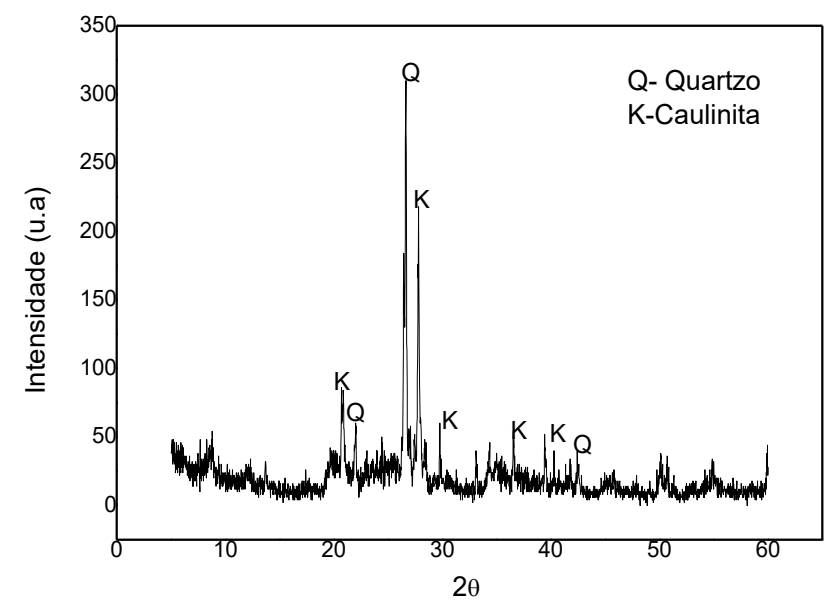

Fonte: Autores (2021).

Com base na Figura 3, por meio da análise de difração de raio $-X$, o rejeito da diatomita apresentou uma formação de fases cristalinas além de manter o caráter amorfo característico do material, com picos de quarzo $\left(\mathrm{SiO}_{2}\right)$, assim como a presença de caulinita $\mathrm{Al}_{2} \mathrm{Si}_{2} \mathrm{O}_{5}(\mathrm{OH})_{4}$ proveniente do material argiloso. É importante destacar que a morfologia foi tipo navicular, uma característica deste material. A diatomita consiste em partículas cilíndricas com um estrutura celular quadrada e superfície composta por microporos, justificando a, justificando a alta porosidade e baixa densidade deste material, como foi observado em estudos anteriores (Posi, et al., 2013). 
Figura 3 - Difratograma de raios- X do rejeito de diatomita.

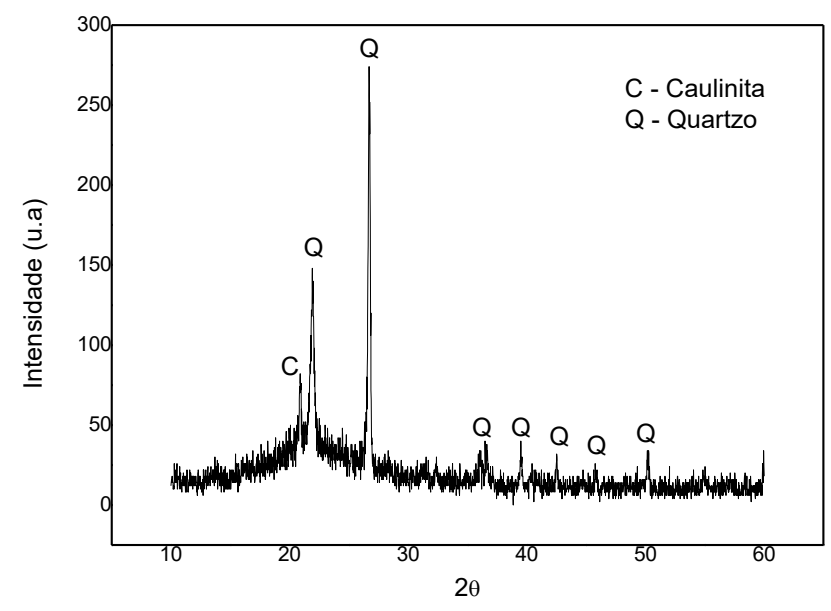

Fonte: Autores (2021).

\section{Influência dos parâmetros sobre a umidade}

O processo de secagem foi realizado conforme descrito na secção de materiais e métodos. Os dados de perda de massa das amostras para todas as condições apresentadas na Tabela 1 foram convertidos em teor de umidade pela Equação 1. Para cada replica, foi calculado a média dos cinco corpos de prova e o resultado está disponível na Tabela 4.

Tabela 4 - Resultados da umidade para o planejamento experimental.

\begin{tabular}{lcccccc}
\hline & & & & \multicolumn{3}{c}{ Resultados [s] } \\
\hline Experimento 1 & $\mathrm{P}[\%]$ & $\mathrm{T}\left[{ }^{\circ} \mathrm{C}\right]$ & $\mathrm{H}[\mathrm{min}]$ & Amostra 1 & Amostra 2 & Amostra 3 \\
\hline Experimento 2 & 10 & 110 & 30 & 0,012 & 0,016 & 0,013 \\
Experimento 3 & 10 & 60 & 30 & 0,142 & 0,168 & 0,171 \\
Experimento 4 & 10 & 60 & 60 & 0,190 & 0,209 & 0,202 \\
Experimento 5 & 30 & 110 & 30 & 0,025 & 0,014 & 0,015 \\
Experimento 6 & 30 & 110 & 60 & 0,008 & 0,007 & 0,010 \\
Experimento 7 & 30 & 60 & 30 & 0,125 & 0,110 & 0,111 \\
Experimento 8 & 30 & 60 & 60 & 0,134 & 0,134 & 0,134 \\
\hline
\end{tabular}

Fonte: Autores (2021).

Para analisar os efeitos de cada parâmetros sobre o teor de umidade após o período de secagem, construiu-se, a partir dos resultados do planejamento experimental um diagrama de Pareto dos efeitos padronizados com significância estatística de 99,99\%, conforme apresentado na Figura 4. 
Figura 4 - Diagrama de Pareto para os parâmetros avaliados.

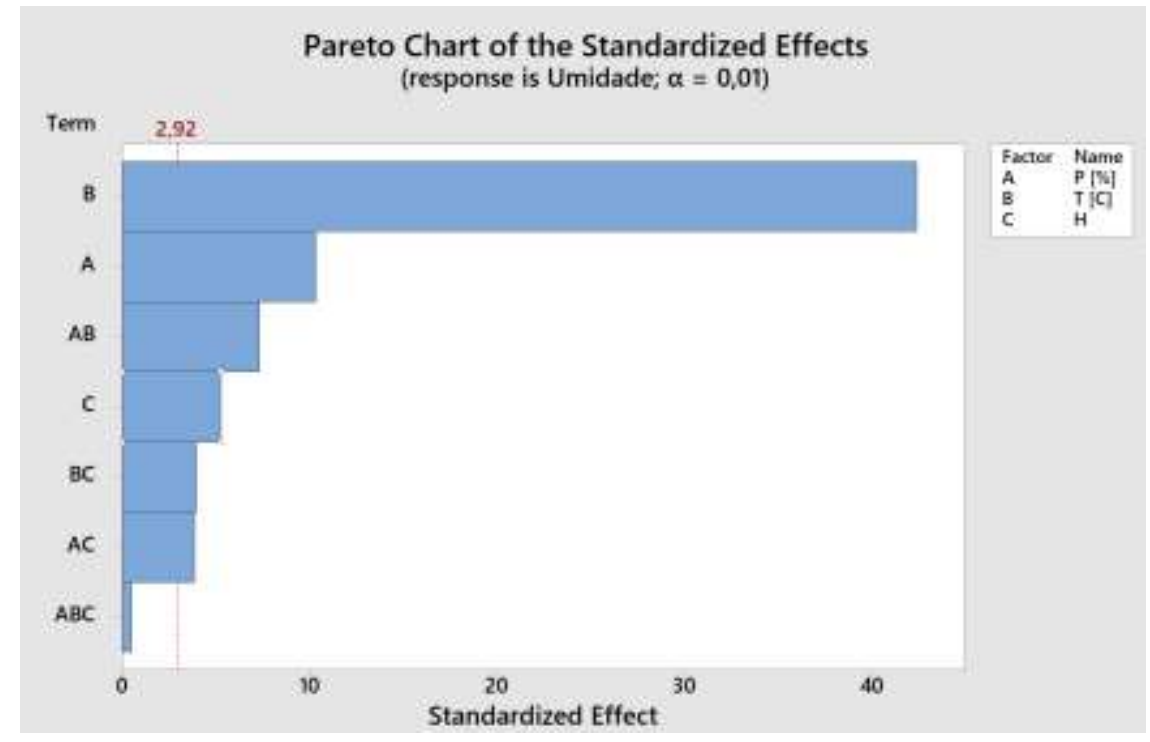

Fonte: Autores (2021).

Analisando a Figura 4, observamos que o efeito da temperatura tem uma influência muito maior do que os demais parâmetros analisados, tal comportamento ocorre porque a transferência de calor é um fenômeno que induz e controla a transferência de umidade em uma operação de secagem. Depois da temperatura, a porcentagem de diatomita é o segundo parâmetro que mais tem efeito sobre a redução da umidade durante a secagem, indicando que a quantidade de rejeito que é introduzido nos tijolos cerâmicos afeta diretamente sua secagem. O efeito da homogeneização e as interações entre os parâmetros também podem afetar a secagem dos tijolos cerâmicos, mas em proporções muito menores do que os dois primeiros parâmetros.

Foi avaliado como cada parâmetro individualmente afeta o teor de umidade final das amostras e o resultado foi plotado no gráfico que é apresentado na Figura 5.

Figura 5 - Gráfico das variações de umidade pela variação dos parâmetros avaliados.

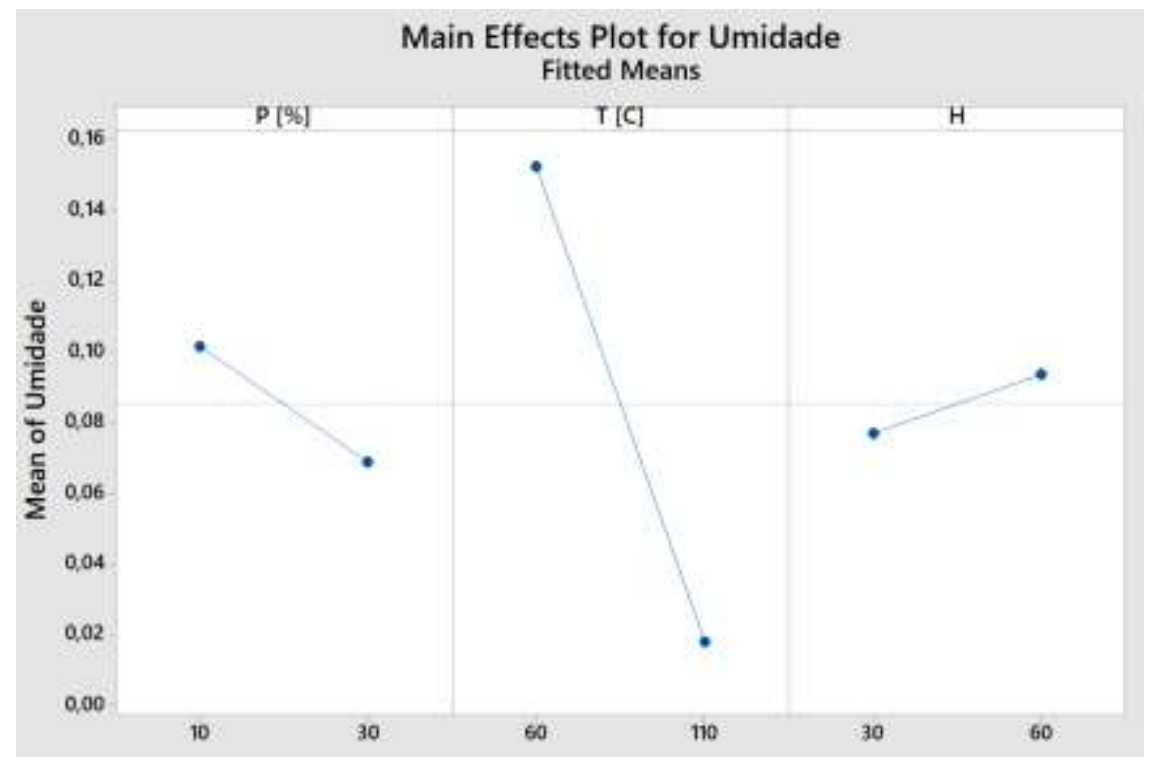

Fonte: Autores (2021). 
Observando o comportamento individual de cada parâmetro, podemos verificar que conforme apresentado no diagrama de Pareto, a temperatura apresenta a maior influência dentre os demais parâmetros avaliados, onde ocorre uma queda brusca de umidade quando se aumenta a temperatura da secagem, saindo de $15,25 \%$ de umidade a $60^{\circ} \mathrm{C}$ para $1,79 \%$ de umidade quando o tijolo foi secado a $110^{\circ} \mathrm{C}$.

Quando aumentado o teor de rejeito nos tijolos cerâmicos, observou-se uma da umidade após a secagem dos tijolos cerâmicos, porém, em valores bem menores quanto comparados a queda de umidade na variação de temperatura, o que está em concordância com os resultados obtidos no diagrama de Pareto. Tendo sido verificado 6,88\% de umidade para os corpos de prova com $30 \%$ de rejeito, enquanto os corpos de prova com $10 \%$ de rejeito apresentaram, $10,16 \%$ de umidade. Tal comportamento pode ser explicado pela maior porosidade do rejeito em relação argila, o que facilita a migração da água do interior do tijolo para a parte externa, onde será evaporada.

Ao contrário do que foi observado nos parâmetros de temperatura e porcentagem de rejeito, a homogeneização da massa apresentou um aumento de umidade quando foi aumentado o tempo de homogeneização, o que implica que quanto mais homogênea a massa estiver, maior a dificuldade de se retirar água do interior do tijolo. $\mathrm{O}$ aumento da umidade com o aumento do tempo de homogeneização, teve uma variação menor do que os parâmetros de temperatura e porcentagem de rejeito, saindo de 7,69\% com uma homogeneização de 30 min para 9,35\% com uma homogeneização de 60 min.

Analisamos ainda como a interação entre os parâmetros estudados afeta o teor de umidade final das amostras, sendo esse resultado apresentado no gráfico da Figura 6.

Figura 6 - Gráfico das variações de umidade pela interação entre os parâmetros avaliados.

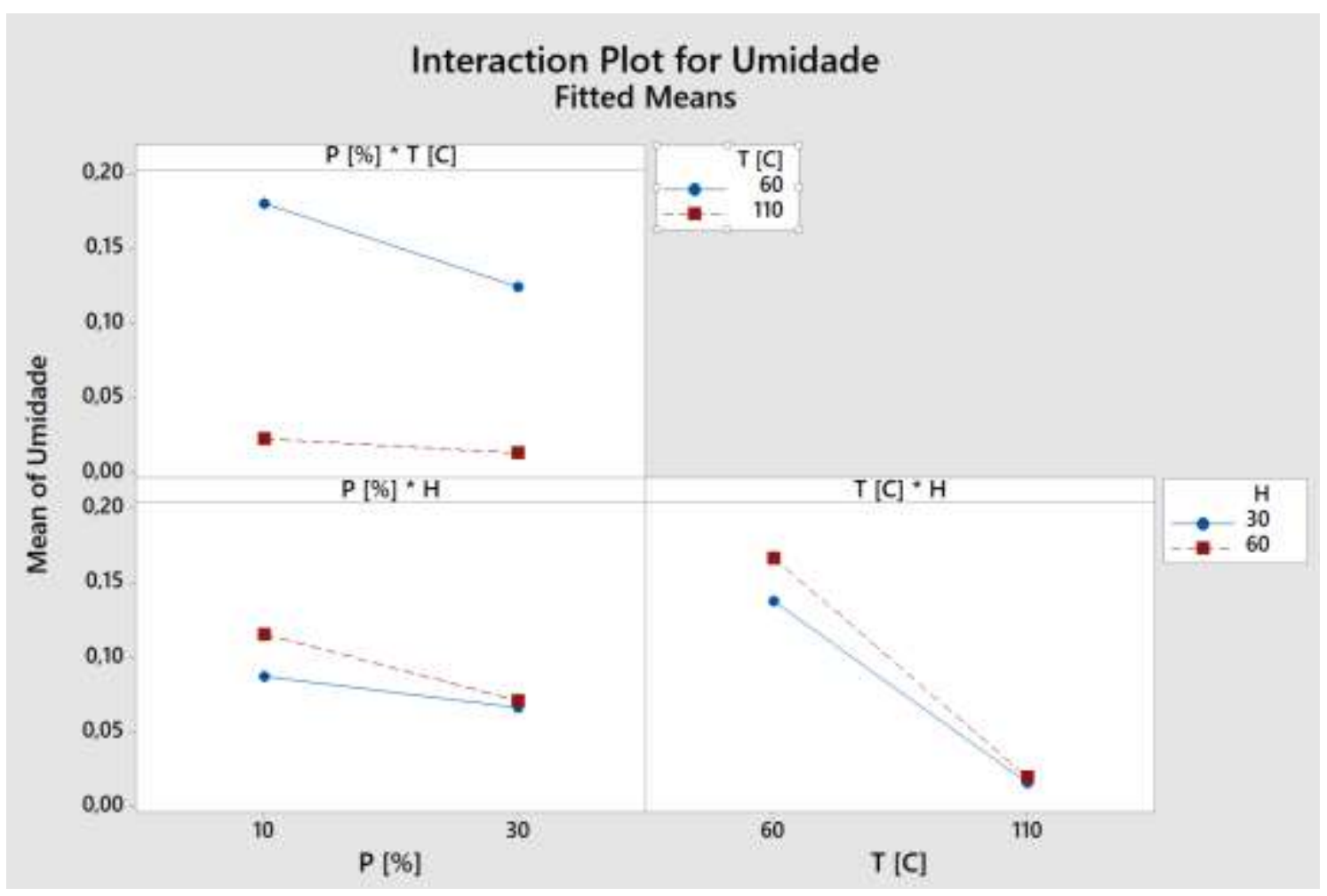

Fonte: Autores (2021).

Observa-se, na interação da porcentagem de rejeito com a temperatura, que para a temperatura de $60^{\circ} \mathrm{C}$ o efeito da quantidade de rejeito, é maior do que para a temperaturas de $110^{\circ} \mathrm{C}$, pois devido ao aumento da porosidade decorrente ao incremento do rejeito da diatomita, a água consegue sair mais facilmente do interior do tijolo, precisando de menos energia 
para isso. Para a secagem a $110^{\circ} \mathrm{C}$, a energia fornecida para o tijolo consegue retirar uma grande quantidade de umidade, que ao aumentar a porcentagem de rejeito na amostra e consequentemente a porosidade do material, a influência dessa adição é pequena.

$\mathrm{Na}$ interação entre a porcentagem de rejeito com o tempo de homogeneização, observa-se que para valores baixos de rejeito nas amostras o tempo de homogeneização elevado se mostrou com um parâmetro que dificulta a saída da água durante a secagem, apresentando maiores valores de umidade para maiores tempos de homogeneização, porém quando se aumenta a porcentagem do rejeito, observa-se que o teor de umidade presente nas amostras ao fim da secagem é menor tanto para o tempo de homogeneização de 30 min quanto para o tempo de $60 \mathrm{~min}$, chegando a valores muito próximos quando comparados os dois tempos.

Na interação entre temperatura e tempo de homogeneização, observa-se que para a temperatura mais baixa, existe uma maior umidade na amostra de maior tempo de homogeneização da massa. Quando eleva-se para a temperatura de $110^{\circ} \mathrm{C}, \mathrm{o}$ tempo de homogeneização passa a não ter uma grande influência, pois observa-se uma queda de umidade na amostra que tinha o maior tempo de homogeneização, e os valores de umidade se aproximam das amostras de menor tempo de homogeneização, tal fenômeno pode ter sido acarretado pela maior quantidade de água presente nessa amostra, o que facilitou a sua evaporação em temperaturas maiores, chegando assim ao teor de umidade mínimo para essa temperatura.

A partir dos dados coletados durante os experimentos, construiu-se a curva de secagem para todos os 8 ensaios do planejamento experimental apresentado na Tabela 1. A curva está sendo apresentada na Figura 7.

Figura 7 - Curva de secagem para os experimentos da Tabela 1.

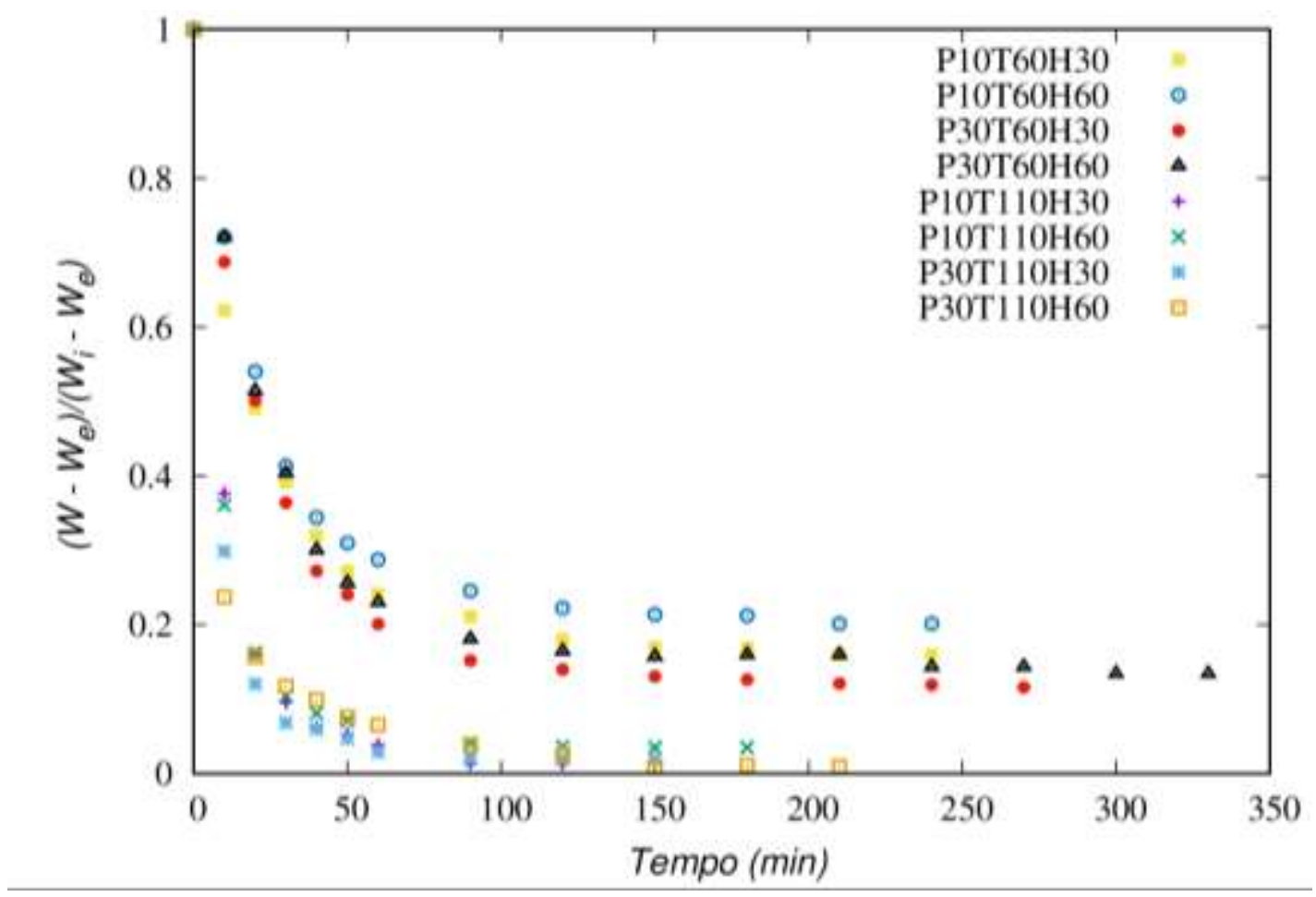

Fonte: Autores (2021).

Analisando a Figura 7, podemos observar o efeito da influência da temperatura durante a secagem dos tijolos cerâmicos, onde as 4 curvas que representam a temperatura de $60^{\circ} \mathrm{C}$ estão um pouco acima das curvas de $110^{\circ} \mathrm{C}$, o que significa uma maior presença de água nos corpos de prova, resultado esse que já foi observado na Figura 7. Explorando as curvas de $60^{\circ} \mathrm{C}$, também podemos perceber o efeito da porcentagem do rejeito de diatomita e o efeito do tempo de 
homogeneização do meio. Quando comparamos a curva P10T60H30 com a curva P30T60H30, observamos que esta última está abaixo da primeira, o que significa que ela perde mais umidade durante a secagem devido ao incremento do rejeito nos tijolos cerâmicos, resultado esse que também tinha sido identificado nas análises anteriores. Comparando agora as curvas P10T60H30 e P10T60H60 ou a curva P30T60H30 com a curva P30T60H60, ratificamos os resultados obtidos anteriormente, onde havíamos observado que quanto maior o tempo de homogeneização do material, menor é a facilidade de perder água durante a secagem.

As curvas da temperatura de $100^{\circ} \mathrm{C}$, repetem o mesmo comportamento das curvas de $60^{\circ} \mathrm{C}$ para a análise do tempo de homogeneização e a porcentagem de rejeito nos tijolos, porém, com diferenças menos significativas entre elas, obtendo praticamente o mesmo teor de umidade na parte final da secagem.

\section{Conclusão}

$\mathrm{Na}$ composição química da argila e rejeito estudados em ambas há presença de alumina que é indicativo da necessidade da realização de estudos aos ataques químicos, pois em meios agressivos essa alumina pode reagir e desencadear patologias.

Os rejeitos minerais oriundos do beneficiamento da diatomita apresentaram propriedades físicas adequadas para serem utilizados na confecção de massas de cerâmicas vermelhas, destacando-se por terem uma menor quantidade de finos. Logo, a massa cerâmica obtida com esse rejeito demandará uma menor quantidade de água e, consequentemente, menor retração.

Na composição mineralógica da argila e do rejeito estudados ocorreu a predominância do quartzo, oriundo da sílica cristalina presente na composição química desses.

A partir da análise do planejamento experimental fatorial $2^{3}$ e dos resultados do processo de secagem dos tijolos cerâmicos, concluiu-se que: a temperatura é o principal parâmetro que controla a retirada de umidade do material; $30 \%$ de rejeito proporcionou maior facilidade para a eliminação da água presente nas amostras. O inverso ocorre em relação ao tempo de homogeneização, no qual observamos que quanto maior o seu tempo, menos umidade se perde.

Como sugestão para trabalhos futuros, recomenda-se aplicar a secagem em tijolos cerâmicos vazados, com diferentes relações de composição do rejeito de diatomita/argila, analisando os efeitos das tensões termomecânicas e sua aplicabilidade na indústria da construção civil.

\section{Referências}

Almeida, K. S., Soares, R. A. L., \& Matos, J. M. E. (2020). Efeito de resíduos de gesso e de granito em produtos da indústria de cerâmica vermelha: revisão bibliográfica. Revista Matéria, 25 (1). 10.1590/s1517-707620200001.0893

Alves, H. J., Melchíades, F. G., \& Boschi, A. O. (2008). Consumo de gás natural na indústria de revestimentos cerâmicos brasileira. Cerâmica. 54, (331), 326331. 10.1590/S0366-69132008000300009

Barreira, E., Delgado, J. M. P. Q., \& Freitas, V. P. (2015). Wetting and Drying of Building Materials. Drying and Wetting of Building Materials and Components, 3, 51-69. 10.1007/978-3-319-04531-3_3

Boukadida, N., Nasrallah, S. B., \& Perre, P. (2007). Mechanism of two-dimensional heat and mass transfer during convective drying of porous media under different drying conditions. Drying Technology 18 (7), 1367 - 1388. 10.1080/07373930008917783

Cadé, M. A., Nascimento, J. J. S., \& Lima, A. G. B. (2005). Drying of Holed Ceramic Bricks: An Approach by Finite-Volumes. Matéria. 10 (3), 443 - 453. http://www.materia.coppe.ufrj.br/sarra/artigos/artigo10682

Crangle, R. D. (2014). Diatomite U.S. Geol. (2014). Surv. Miner. Commodity Summaries,52-53.

Degirmenci, N., \& Yilmaz, A. (2009). Use of diatomite as partial replacement for Portland cement in cement mortars. Construction and Building Materials, 23 (1), 284-288. 10.1016/j.conbuildmat.2007.12.008

França, S. C. A., \& Luz, A. B. (2002). Beneficiamento de diatomita da Bahia. Série Rochas e Minerais Industriais, 7. http://www. http://mineralis.cetem.gov.br/handle/cetem/583 
Research, Society and Development, v. 10, n. 8, e13710817174, 2021

(CC BY 4.0) | ISSN 2525-3409 | DOI: http://dx.doi.org/10.33448/rsd-v10i8.17174

Gameiro, F., Brito, J., \& Silva, D.C. (2014). Durability performance of structural concrete containing fine aggregates from waste generated by marble quarrying industry. Engineering Structures, 59, 654-662. 10.1016/j.engstruct.2013.11.026

Goulart, M. R. (2010). Metodologias para reutilização do resíduo industriais, terra de diatomácea, proveniente da filtração e clarificação da cerveja. Dissertação (Mestrado em ciência do solo), Universidade do Estado de Santa Catarina-UDESC, Lages, Santa Catarina, Brasil.

Hadjar, H., Hamdi, B., Jaber, M., Brendlé, J., Kessaissia, Z., Balard, H., \& Donnet, J. B. (2008). Elaboration and characterisation of new mesoporous materials from diatomite and charcoal. Microporous Mesoporous Materials, 107 (3), 219-226. 10.1016/j.micromeso.2007.01.053

Macedo, A. R. S., Silva, A. S., Da luz, D. S., Ferreira, R. L. S., Lourenço, C. S., \& Gomes, U. U. (2020). Estudo do efeito da diatomita nas propriedades físicomecânicas do concreto. Cerâmica ,66 (337), 50-55. 10.1590/0366-69132020663772561

Medeiros, F. K., Aquino, R. C. A., Rodrigues, A. M. T., Silva, H. C., Dias, I. B. C., \& Ferreira, H. S. (2014). Produção de Tijolos Maciços e Placas Cerâmicas de Revestimento com Adição de Óleo Lubrificante Usado. Cerâmica Industrial, 19 (2), 38-45. 10.4322/cerind.2014.071

Monteiro, F. M., Costa, F. A., Machado, T. G., \& Assis, R. B. (2017). Caracterização de argila caulínitica da região metropolitana de Natal-RN - parte 1. 72 ${ }^{\circ}$ ABM Annual Congres, 72, 3658-3669. 10.5151/1516-392X-30958

Monteiro, S. N., \& Vieira, C. M. F. (2005). Effect of oily waste addition to clay ceramic. Ceramics International, 31 (2), 353-358. 10.1016/j.ceramint.2004.05.002

Nascimento, J. J. S. Fenômenos de difusão transiente em sólidos paralelepípedos. Estudo de caso: Secagem de materiais cerâmicos. 2002. Tese (Doutorado em engenharia mecânica) - Universidade federal da paraíba- Joao pessoa, Paraíba, Brasil.

Nascimento, J. J. S., Lima, A. G. B., Teruel, B. J., \& Belo, F. A. (2006). Inf. Tecnol. 17 (6), 145-151.

Nociti, D. M. (2011). Aproveitamento de rejeitos oriundos da extração de minério de ferro na fabricação de cerâmicas vermelhas. Dissertação (Mestrado em engenharia mecânica na área de materiais) - Universidade Estadual Paulista, Guaratinguetá, São Paulo, Brasil.

Posi, P., Lertnimoolchai, S., Sata, V., \& Chindaprasirt, P. (2013). Constr. Build. Mater. 47, 896.

Reis, A. S., Oliveira, J. N., Della-sagrillo, V. P., \& Valenzuela-diaz, F. R. (2014). Caracterização e avaliação das propriedades cerâmicas de argila utilizada em cerâmica estrutural. Anais do $21^{\circ}$ CBECIMAT - Congresso Brasileiro de Engenharia e Ciência dos Materiais, Cuiabá, MT, Brasil.

Rodrigues, L. R., Rodrigues, E. R., Albani, C. B., Dos Reis, A. S., Louzada, D. M., \& Sagrillo, D. V. P. (2019). Resíduo do processo Kraft (dregs) como matéria-prima alternativa para cerâmica vermelha. Cerâmica, 65 (373), 162-169. 10.1590/0366-69132019653732431

Souza Santos P. (1975). Tecnologia das argilas. São Paulo: Edgard Blucher, Vol.1-2.

Schackow, A., Stringari, D., Senff, L., Correia, S. L., \& Segadães, A. M. (2015). Influence of fired clay brick waste additions on the durability of mortars. Cement \& Concrete Composites, 62, 82-89. 10.1016/j.cemconcomp.2015.04.019

Zlatanović, I., Komatina, M., \& Antonijević, D. (2013). Low-temperature convective drying of apple cubes. Applied Thermal Engineering, 53 (1), 114-123. 10.1016/j.applthermaleng.2013.01.012

Wang, J., Law, C., Nema, P. K., Zhao, J., Liu, Z., Gao, Z., \& Xiao, H. (2018). Pulsed vacuum drying enhances drying kinetics and quality of lemon slices. Journal of Food Engineering, 224, 129-138. 10.1016/j.jfoodeng.2018.01.002 